\title{
EGFR Mutant-specific Inhibitor CK-101
}

National Cancer Institute

\section{Source}

National Cancer Institute. EGFR Mutant-specific Inhibitor CK-101. NCI Thesaurus. Code C132023.

An orally available third-generation and selective inhibitor of certain epidermal growth factor receptor (EGFR) activating mutations, including the resistance mutation T790M, and the L858R and del 19 mutations, with potential antineoplastic activity. Upon administration, the EGFR mutant-specific inhibitor CK-101 specifically and covalently binds to and inhibits selective EGFR mutations, with particularly high selectivity against the T790M mutation, which prevents EGFR mutant-mediated signaling and leads to cell death in EGFR mutant-expressing tumor cells. Compared to some other EGFR inhibitors, CK-101 may have therapeutic benefits in tumors with T790M-mediated drug resistance. This agent shows minimal activity ag ainst wild-type EGFR (WT EGFR), and does not cause dose-limiting toxicities that occur during the use of non-selective EGFR inhibitors, which also inhibit WT EGFR. EGFR, a receptor tyrosine kinase mutated in many tumor cell types, plays a key role in tumor cell proliferation and tumor vascularization. 